\title{
Developmental Changes in Enzyme Activities in Fetal and Neonatal Rabbit Lung. Cytidylyltransferase, Cholinephosphotransferase, Phospholipases $A_{1}$ and $A_{2}, \beta$-Galactosidase, and $\beta$-Glucuronidase
}

\author{
M. F. HEATH ${ }^{(65)}$ AND W. JACOBSON \\ University of Cambridge Clinical School, Department of Paediatrics, Cambridge, United Kingdom
}

\section{Summary}

Lungs were obtained from rabbit fetuses (on each day from d 24 to $\mathbf{d} 30$ of gestation), neonates and adults, and were fractionated for enzyme assays. The developmental profile of cytidyltransferase shows a decrease in specific activity from d 25 to d $29(P<0.05)$ then a sharp rise from $\mathrm{d} 30$ to adult values in $\mathrm{d} 0$ neonates $(P<0.05)$. Cholinephosphotransferase specific activity changes little from d 25 to birth, apart from a non-significant peak on $\mathrm{d} 29$. There is a sharp rise from neonatal $\mathrm{d} 0$ to adult values on $\mathrm{d} 1(P<0.01)$. The specific activity of microsomal phospholipase $A_{2}$ declines from $d 25$ to reach adult values in the neonate $(P=0.05)$. In contrast, the specific activity of lysosomal phospholipase $A_{2}$ rises from d 24-28 then falls in the neonate ( $P$ $<0.05)$. Adult values are higher than those in the fetus and neonate. Three other lysosomal enzyme specific activities rise to d 28 then decline: phospholipase $A_{1}, \beta$-galactosidase, and $\beta$ glucuronidase. The results demonstrate that the level of microsomal phospholipase $A_{2}$ does not control the extent of remodelling of phosphatidylcholine for surfactant production. Lysosomal phospholipase $\mathrm{A}_{2}$ only increases in parallel with the other lysosomal enzymes, indicating an increase in the number of lysosomes in the lung.

In his review of the metabolism of phospholipids in the lung, van Golde (57) pointed out that the pathways of de novo synthesis of phosphatidylcholine yield predominantly unsaturated molecular species, and could not supply all the saturated (dipalmitoyl) phosphatidylcholine needed for the production of pulmonary surfactant. Sufficient dipalmitoyl phosphatidylcholine could be obtained by "remodelling" the unsaturated material. In such a process, the action of phospholipase $\mathrm{A}_{2}$ (EC 3.1.1.4) would remove the unsaturated fatty acid from the 2-position of phosphatidylcholine, yielding mainly 1-palmitoyl-2-lysophosphatidylcholine, which could then be reacylated with a palmitoyl group to form a molecule of dipalmitoyl phosphatidylcholine. Phospholipase $\mathrm{A}_{2}$ might, therefore, show changes in activity during lung development that would be indicative of its importance in the biosynthesis of dipalmitoyl phosphatidylcholine in fetal and neonatal lungs. It might also be possible that this enzyme could be a site for therapeutic intervention to raise the level of enzyme activity in cases of respiratory distress syndrome of the newborn, in which the rate of synthesis of surfactant is too low to support normal respiration. Alternatively, excessive levels of phospholipase $A_{2}$ activity might result in undesirable surfactant breakdown.

This study looks at the activity of phospholipase $A_{2}$ in developing rabbit lung. The alkaline-optimum enzyme of the microsomal fraction and the acid-optimum enzyme of the lysosomal fraction were assayed separately. In order to provide developmental patterns for comparison, assays were also made of two other enzymes of phosphatidylcholine biosynthesis. These were CTP:phosphocholine cytidylyltransferase (EC 2.7.7.15), usually referred to below simply as cytidylyltransferase, which catalyses the transfer of a cytidylyl group from CTP on to the phosphate of phosphocholine, forming CDPcholine, and CDPcholine:1,2diacylglycerol cholinephosphotransferase (EC 2.7.8.2), referred to as cholinephosphotransferase, which transfers the phosphocholine moiety from CDPcholine on to the free hydroxyl group of a 1,2-diacylglycerol, converting it to a molecule of phosphatidylcholine. For further comparison, three other lysosomal enzymes, namely phospholipase $\mathrm{A}_{1}$ (EC 3.1.1.32), $\beta$-galactosidase (EC 3.2.1.23), and $\beta$-glucuronidase (EC 3.2.1.31), were also assayed. The results are displayed as specific activities in the specified fractions of lung homogenate, and also as total activity in the fraction to demonstrate that large changes in the amounts of other proteins are not responsible for the changes in specific activity.

\section{MATERIALS AND METHODS}

Lung fractionation. The procedures used were modified from our previous work $(24,25)$, in which fractions were prepared from rabbit lung homogenates by differential sedimentation and characterised with marker enzymes. New Zealand White rabbits of $25,26,27,28,29$, and 30 d gestation (accurate to within $2 \mathrm{~h}$ ) were obtained from Pemberley Rabbits, Cambridge, United Kingdom. The does were killed by cervical dislocation or intravenous barbiturate. The uterus was removed and the lungs of each fetus were excised and placed together (one litter) in a weighed beaker of ice cold $0.25 \mathrm{M}$ sucrose in $50 \mathrm{mM}$ Tris. $\mathrm{HCl}$ (pH 7). In some cases, when the doe had been killed by cervical dislocation, the maternal lungs were also removed into a separate beaker of ice cold medium. Some data are also included from Old English rabbits of $24 \mathrm{~d}$ gestation, the lungs from three litters being collected together. Newborn New Zealand White rabbits were killed by decapitation, and the lungs removed and placed together (one litter) in ice cold medium. D 0 represents newborns less than 6-h-old; d 1 represents animals 18-24-h-old.

The beaker plus medium plus lungs were reweighed to determine lung wet weight for the litter. Lungs were rinsed with ice cold medium, chopped with scissors, rinsed again, then homogenised in ice cold $0.25 \mathrm{M}$ sucrose, $50 \mathrm{mM}$ Tris $\cdot \mathrm{HCl}$ (pH 7) (10 $\mathrm{ml} / \mathrm{g}$ with a minimum of $90 \mathrm{ml}$ ) for $2 \times 30 \mathrm{~s}$ with a Silverson homogeniser (Silverson Machines Ltd., Chesham, Bucks., United Kingdom). Homogenates of adult lung were filtered through four layers of muslin. The homogenate was centrifuged at $5000 \mathrm{~g}$ for 
$20 \mathrm{~min}$, and the resulting supernatant was recentrifuged at 13,000 $g$ for $20 \mathrm{~min}$. This pellet was resuspended in $1 \mathrm{mM} \mathrm{Na}{ }_{2}$ EDTA, $1 \mathrm{mM} \mathrm{NaHCO}$, frozen and thawed five times, and dialysed overnight against $1 \mathrm{mM} \mathrm{Na}{ }_{2}$ EDTA and $1 \mathrm{mM} \mathrm{NaHCO}$. After centrifugation at $100,000 \mathrm{~g}$ for $120 \mathrm{~min}$, the resulting supernatant, fraction LS, contained the soluble proteins from lung lysosomes. The supernatant from the $13,000 \mathrm{~g}, 20$-min centrifugation was recentrifuged at $100,000 \mathrm{~g}$ for $120 \mathrm{~min}$. This pellet was resuspended in $50 \mathrm{mM}$ Tris. $\mathrm{HCl}(\mathrm{pH} 7.5), 250 \mathrm{mM} \mathrm{NaCl}$, by two passes of a Dounce homogeniser, to yield fraction $\mathrm{M}$, containing lung microsomes. The corresponding supernatant, fraction $\mathrm{S}$, contained lung cytosol.

Small samples of chopped lung were taken for histologic examination. Samples of lung fractions were dialysed against distilled water, then assayed for protein by the method of Lowry et al. (33) as modified by Campbell and Sargent (10), using as reference a Protein Standard Solution (Sigma London Chemical Co. Ltd., Poole, Dorset, United Kingdom).

Cytidylyltransferase assay. The assay conditions were based on those of Sundler (53), and Rooney et al. (45). In a final volume of $0.5 \mathrm{ml}$, and with continuous shaking at $37^{\circ}, 0.4 \mathrm{ml}$ of fraction $\mathrm{S}$ were incubated in $20 \mathrm{mM}$ Tris succinate (pH 7.5), 10 $\mathrm{mM} \mathrm{MgCl} 2,5 \mathrm{mM} \mathrm{CTP}$ sodium salt (Sigma), and $1 \mathrm{mM}$ phosphocholine chloride calcium salt (Sigma), containing $50 \mathrm{nCi}$ phospho[methyl- $\left.{ }^{14} \mathrm{C}\right]$ choline $(55 \mathrm{Ci} / \mathrm{mol}$; NEN Chemicals $\mathrm{GmbH}$, Dreieich, W. Germany). Samples of $0.1 \mathrm{ml}$ were taken at $0,10,20$, and $40 \mathrm{~min}$, and heated at $90^{\circ}$ for $5 \mathrm{~min}$ to precipitate protein. After cooling, the addition of carrier phosphocholine and CDPcholine, and centrifugation, the supernatant was applied to silica gel thin layer chromatographic plates (Type LK5D from Whatman Laboratory Products Ltd., Maidstone, Kent, United Kingdom), which were developed in ethanol:water:ammonia solution (specific gravity, 0.88) (100:97.5:2.5, by vol) [modified from Sundler (53)]. The substrate and product spots were located by exposing the plate to iodine vapour, and scraped off for scintillation counting. The extent of the reaction was proportional to time for at least $40 \mathrm{~min}$, and to protein concentration over the range used. No activity was seen in the absence of added protein. In order to reduce the tailing caused by sucrose on thin layer chromatography, it was necessary to dialyse fraction $S$ overnight against $100 \mathrm{mM}$ ammonium acetate. This had no effect on the enzyme activity.

Cholinephosphotransferase assay. The assay conditions were modified from Oldenborg and van Golde (41). In a final volume of $0.5 \mathrm{ml}$, and with continuous shaking at $37^{\circ}, 0.3 \mathrm{ml}$ of fraction $M$ were incubated in $50 \mathrm{mM}$ Tris. $\mathrm{HCl}\left(\mathrm{pH} 8.0\right.$ at $\left.37^{\circ}\right), 20 \mathrm{mM}$ $\mathrm{MgCl}_{2}, 5 \mathrm{mM}$ EGTA [ethyleneglycol-bis $(\beta$-aminoethyl ether) $N$, $N, N^{\prime}, N^{\prime}$-tetraacetic acid], $4 \mathrm{mM}$ dithiothreitol, $0.8 \mathrm{mM}$ cytidine5 -diphosphocholine sodium salt (Sigma) containing $250 \mathrm{nCi}$ cytidine- $5^{\prime}$-diphospho[ methyl $\left.-{ }^{14} \mathrm{C}\right]$ choline ammonium salt $(60.9$ $\mathrm{Ci} / \mathrm{mol}$; Amersham International Ltd., Amersham, Bucks., United Kingdom), and $12 \mathrm{mM}$ diacylglycerol (prepared from egg phosphatidylcholine and supplied by Koch-Light Ltd., Haverhill, Suffolk, United Kingdom) dispersed in ethanol/ Triton X-100/ water according to Rooney and Wai-Lee (44). The addition of EGTA and the increased $\mathrm{Mg}^{2+}$ concentration were to reduce the inhibition of cholinephosphotransferase by $\mathrm{Ca}^{2+}(29)$ and to inhibit the activity of microsomal phospholipases (44). Samples of $0.1 \mathrm{ml}$ were taken at $0,5,10$, and $20 \mathrm{~min}$, and mixed with $0.35 \mathrm{ml}$ chloroform: methanol $(1: 2, \mathrm{v} / \mathrm{v})$ for extraction of lipids (7). Phosphatidylcholine $(25 \mu \mathrm{g})$ was added as carrier. The extracted phospholipids were separated by thin layer chromatography on Whatman LK5D plates with chloroform: methanol:water $(65: 25: 4$, by vol.). Phosphatidylcholine was located by exposing the plate to iodine vapour, and the spot was scraped off for scintillation counting. The extent of the reaction was proportional to protein concentration over the range used, but not proportional to time, so the rate of reaction over the first $5 \mathrm{~min}$ was used to determine enzyme activity. No activity was seen in the absence of added protein.
Lysosomal phospholipase $A_{1}$ and $A_{2}$ assay. Assays were performed in a similar manner to that previously described $(24,25)$. The substrate was 1 -palmitoyl-2- $\left[2-{ }^{14} \mathrm{C}\right]$ oleoyl phosphatidylcholine (55 Ci/mol; Applied Science Laboratories Inc., State College, $\mathrm{PA}$ ) diluted to $1 \mathrm{Ci} / \mathrm{mol}$ with egg phosphatidylcholine (Sigma) and prepared as liposomes by ultrasonication for $3 \mathrm{~min}$. The reaction mixture $(0.2 \mathrm{ml})$ contained $0.1 \mathrm{ml}$ of fraction LS, 0.05 $\mathrm{mM}$ substrate, $40 \mathrm{mM}$ sodium acetate $(\mathrm{pH} 4.0)$, and $5 \mathrm{mM}$ $\mathrm{Na}_{2}$ EDTA. After $1 \mathrm{~h}$ at $37^{\circ}$, with continuous shaking, the reaction was terminated by the addition of $0.3 \mathrm{ml}$ chloroform:methanol $(2: 1, \mathrm{v} / \mathrm{v})$ containing $25 \mu \mathrm{g}$ each of oleic acid and lysophosphatidylcholine. The chloroform layer was separated by centrifugation and analysed by thin layer chromatography on Whatman LK5D plates developed in hexane:chloroform:methanol:acetic acid:water (100:75:25:2:1, by vol.), and the spots corresponding to free fatty acids, phosphatidylcholine and lysophosphatidylcholine were located by exposing the plate to iodine vapour. The spots were scraped off for scintillation counting. Phospholipase $A_{1}$ activity was calculated from the yield of labeled lysophosphatidylcholine, and phospholipase $\mathrm{A}_{2}$ from the yield of labeled free fatty acid.

Microsomal phospholipase $A_{2}$ assay. Assays were performed as for lysosomal phospholipases, with the following differences: incubation of $0.1 \mathrm{ml}$ of fraction $\mathrm{M}$ took place in $50 \mathrm{mM}$ Tris. $\mathrm{HCl}\left(\mathrm{pH} 8.0\right.$ at $37^{\circ}$ ), containing $12.5 \mathrm{mM} \mathrm{CaCl}_{2}$, these conditions corresponding to the broad optima for $\mathrm{pH}$ and $\mathrm{Ca}^{2+}$ concentration shown by the enzyme. The reaction mixture was acidified by the addition of $25 \mu \mathrm{l} 0.6 \mathrm{M} \mathrm{H}_{2} \mathrm{SO}_{4}$ before the extraction of lipids for analysis. The extent of reaction was proportional to time for at least $1 \mathrm{~h}$, and to protein concentration over the range used. Blanks with no added protein were always included. The addition of $1 \mathrm{mM}$ sodium deoxycholate to the incubation medium caused a 14-fold increase in activity, presumably by converting the liposomal substrate to a micellar form. But, because a liposomal substrate was considered to be more relevant physiologically, detergent was not added to the standard assay. Phospholipase $A_{1}$ activity was always insignificant.

$\beta$-galactosidase and $\beta$-glucuronidase assays. Assays were performed as described by Barrett and Heath (3), using 4-nitrophenyl $\beta$-D-galactopyranoside and 4-nitrophenyl $\beta$-D-glucuronide (both from Sigma), respectively, as substrates. In a final volume of $1.5 \mathrm{ml}$, and with continuous shaking at $37^{\circ}, 0.1 \mathrm{ml}$ of fraction LS were incubated in $100 \mathrm{mM}$ sodium acetate $(\mathrm{pH}$ 4.5 ), and $5 \mathrm{mM}$ substrate. After 0,20 , or $40 \mathrm{~min}$ the reaction was stopped by the addition of $1.5 \mathrm{ml} 0.5 \mathrm{M} \mathrm{NaHCO}_{3}, 0.5 \mathrm{M}$ $\mathrm{Na}_{2} \mathrm{CO}_{3}$. The tubes were kept cold and dark until the absorbance at $420 \mathrm{~nm}$ had been determined. The extent of the reaction was proportional to time for at least $40 \mathrm{~min}$, and to protein concentration over the range used. No activity could be detected in the absence of added protein.

\section{RESULTS}

The mean lung wet weight per animal was determined for each litter, and these values were averaged for each time point. No attempt was made to remove blood or any other liquid from the excised lungs before weighing. Lung wet weight increased from $0.36 \mathrm{~g} /$ animal $(n=1)$ on d 24 to $1.43 \pm 0.07 \mathrm{~g} / \mathrm{animal}$ (SEM, $n$ $=4$ ) on $\mathrm{d} 30$. There followed an abrupt fall of $40 \%$ in lung wet weight between $\mathrm{d} 30$ fetuses and d 0 neonates, representing the loss of fluid on conversion to air breathing. The value of lung wet weight for the does studied was $15.9 \pm 1.3 \mathrm{~g}(\mathrm{SEM}, n=5)$. The histologic study confirmed the gestational accuracy of the chronologic ages of the fetuses. The mean litter size for fetal and neonatal New Zealand White rabbits was $7.8 \pm 2.4(\mathrm{SD}, n=32)$. Control experiments showed that the use of barbiturates to kill some of the does did not affect the enzyme levels in fetal lungs.

Cytidylyltransferase. Figure 1 shows the developmental profile of cytidylyltransferase as specific activity in the cytosol fraction, S. Activity declines from d 25 to d 29 (d 28 versus d 29, Student's 
$t$ test: $P<0.05$ ), then rises sharply in neonates (d 30 versus $\mathrm{d} 0$, $P<0.05$ ) to adult values. As shown in Figure 8 , there is a general increase in the total activity per lung.

Cholinephosphotransferase. Figure 2 shows the developmental profile of cholinephosphotransferase as specific activity in the microsomal fraction, M. Activity changes little from d 25 to $\mathrm{d} 0$, apart from a marked peak on d 29. This increase in activity is, however, not significant $(P>0.05)$ relative to either $\mathrm{d} 28$ or d 30. There is a sharp rise to adult levels on $\mathrm{d} 1$ ( $\mathrm{d} 0$ versus $\mathrm{d} 1, P$ $<0.01$ ). Figure 8 shows a steady increase in total activity per lung, with a superimposed (but not significant) peak on d 28 and 29.

Microsomal phospholipase $A_{2}$. Figure 3 shows the developmental profile of the alkaline-active phospholipase $\mathrm{A}_{2}$ as specific activity in the microsomal fraction, $M$. Activity declines from $d$ 25 to reach adult values in the neonate [d 25 versus (day $0+d$ 1), $P=0.05$ ]. Figure 8 shows that the total activity per lung remains nearly constant in the fetus, then declines in the neonate.

Lysosomal phospholipase $A_{2}$. Figure 4 shows the developmen-

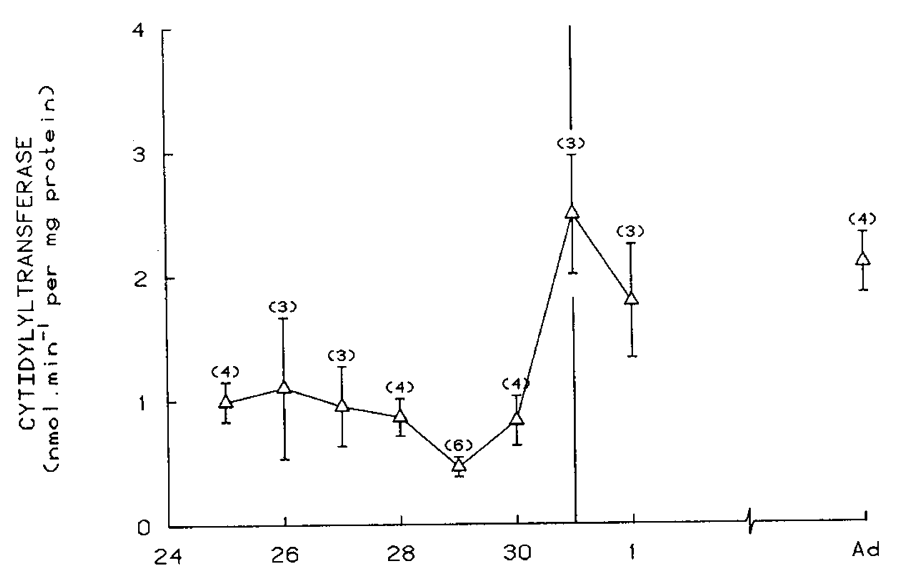

GESTATIONAL AGE (days)

Fig. 1. Cytidylyltransferase, developmental profile of specific activity in cytosol fraction, S. Activity was determined for each litter as described in "Materials and Methods." Values are plotted as mean \pm SEM for each time point. The numbers of litters used are shown in parentheses; Ad, adult. The vertical line marks term (31 d).

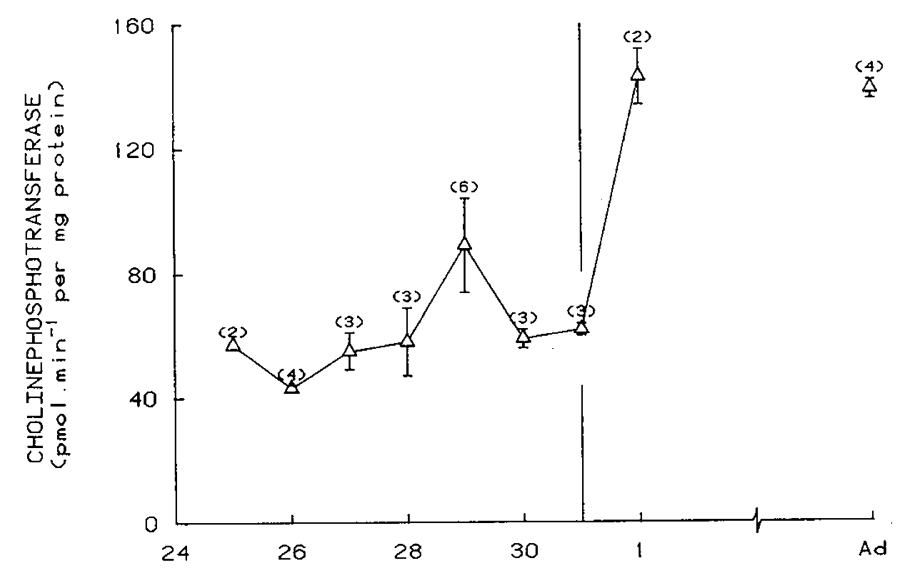

GESTATIONAL AGE (days)

Fig. 2. Chlolinephosphotransferase, developmental profile of specific activity in microsomal fraction, M. For method of presentation, see Figure 1.

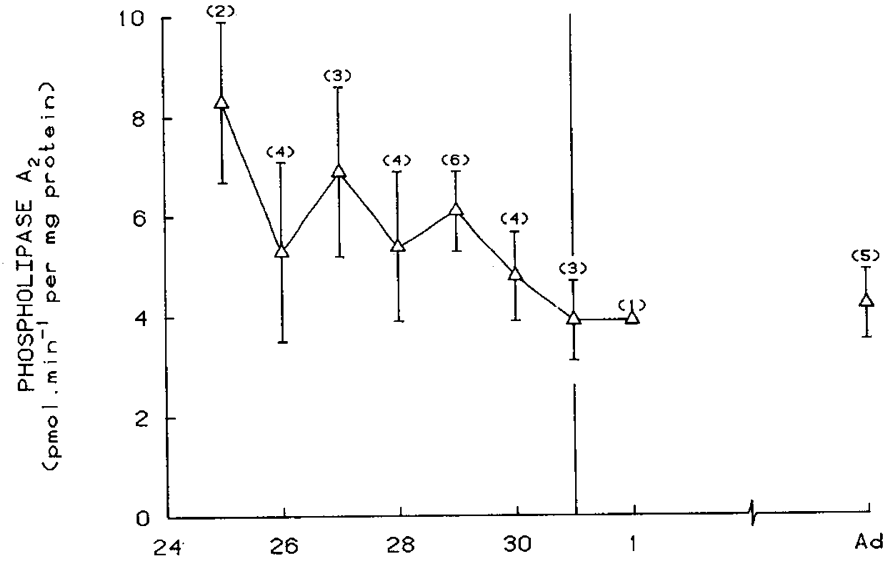

GESTATIONAL AGE (days)

Fig. 3. Alkaline-active phospholipase $A_{2}$, developmental profile of specific activity in microsomal fraction, M. For method of presentation, see Figure 1.

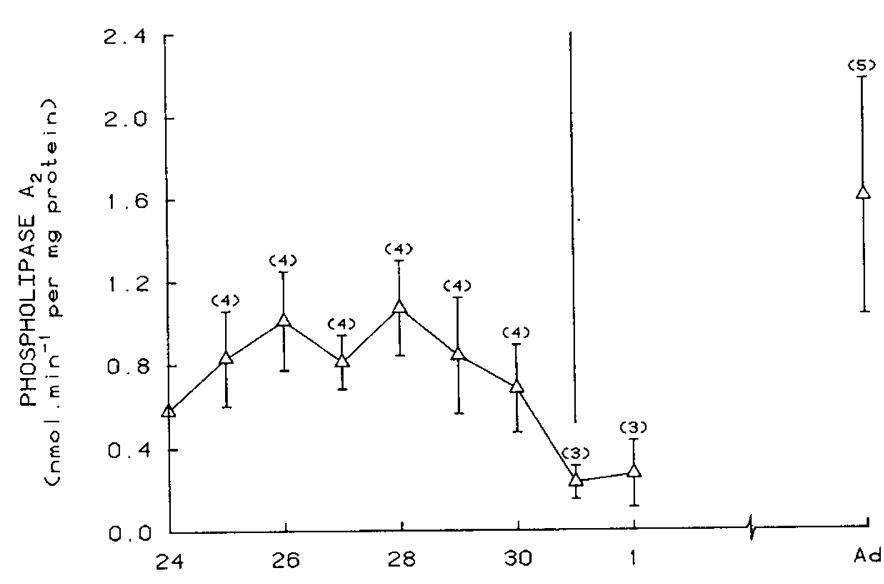

GESTATIONAL AGE (days)

Fig. 4. Acid-active phospholipase $A_{2}$, developmental profile of specific activity in lysosome soluble fraction, LS. For method of presentation, see Figure 1.

tal profile of the acid-active phospholipase $\mathrm{A}_{2}$ as specific activity in the lysosome soluble fraction, LS. Activity rises initially (but d 25 versus d 28 , not significant) then falls steeply in the neonate (d 28 versus d $0, P<0.05$ ). Adult values are generally higher. A similar profile is seen for total activity (Fig. 9).

Lysosomal phospholipase $A_{1}$. Figure 5 shows the developmental profile of acid phospholipase $A_{1}$ as specific activity in the lysosome soluble fraction, LS. The profile generally resembles that for phospholipase $\mathrm{A}_{2}$ (but $\mathrm{d} 28$ versus $\mathrm{d} 0$, not significant), as does the total activity per lung profile (Fig. 9).

$\beta$-galactosidase and $\beta$-glucuronidase. Figures 6 and 7 show the developmental profiles of these glycosidases as specific activity in the lysosome soluble fraction, LS. Activity rises initially (d 25 versus $\mathrm{d} 28, P<0.05$ for each enzyme) then falls in the neonates (but $\mathrm{d} 28$ versus $\mathrm{d} 0$, each not significant). The activities in adults are relatively less elevated than was the case with the phospholipases (Figs. 4 and 5). The similarity of profiles of total activity per lung can be seen in Figure 9. All four lysosomal enzymes studied rise to peaks on $\mathrm{d} 28$, and decline thereafter. 


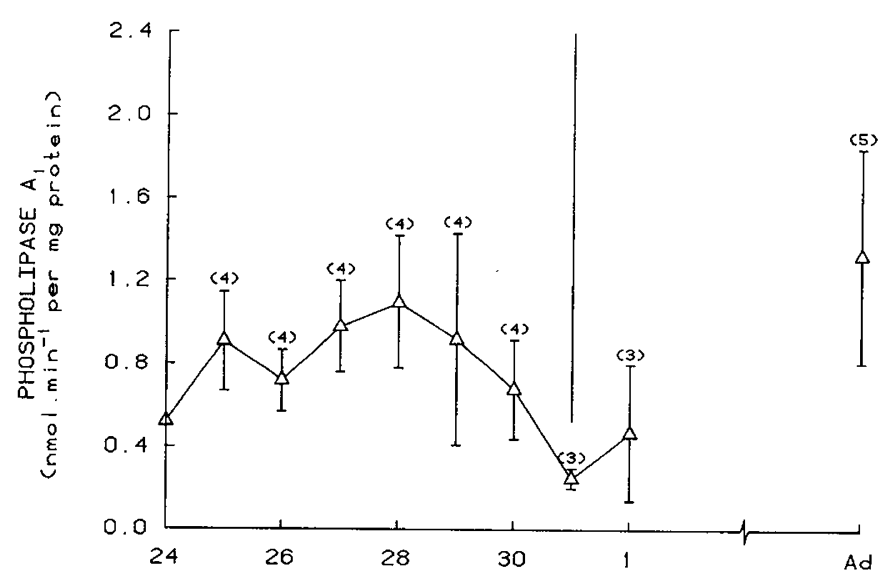

GESTATIONAL AGE (days)

Fig. 5. Phospholipase $A_{1}$, developmental profile of specific activity in lysosome soluble fraction, LS. For method of presentation, see Figure 1.

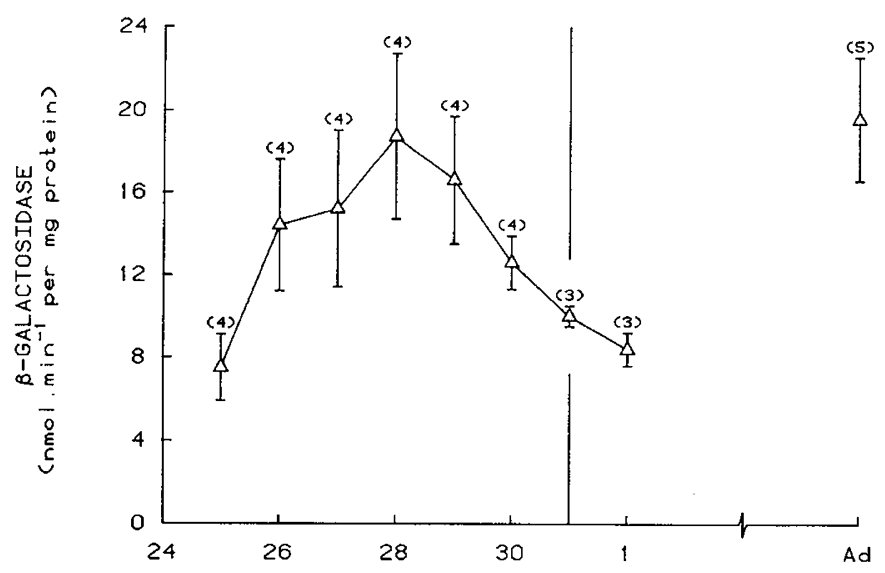

GESTATIONAL AGE (days)

Fig. 6. $\beta$-galactosidase, developmental profile of specific activity in lysosome soluble fraction, LS. For method of presentation, see Figure 1.

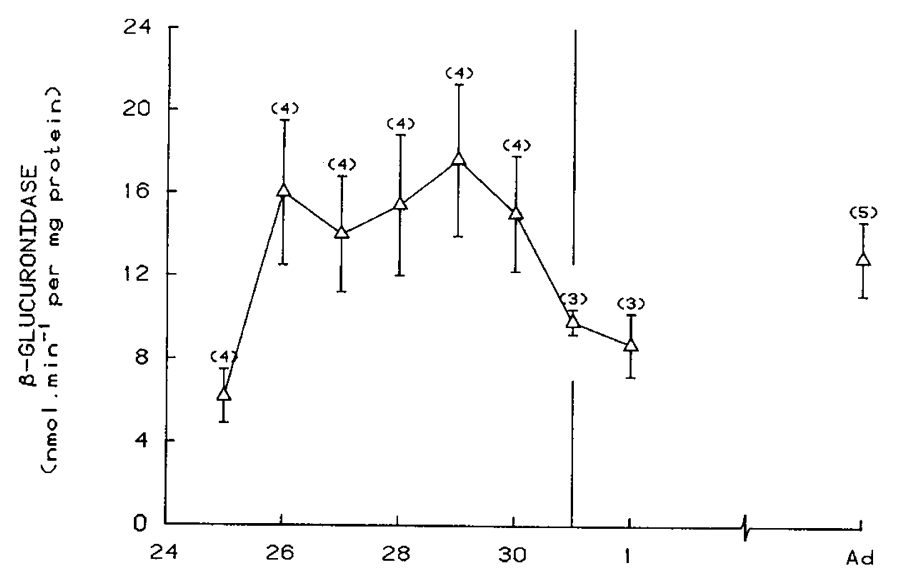

GESTATIONAL AGE (days)

Fig. 7. $\beta$-glucuronidase, developmental profile of specific activity in lysosome soluble fraction, LS. For method of presentation, see Figure 1.

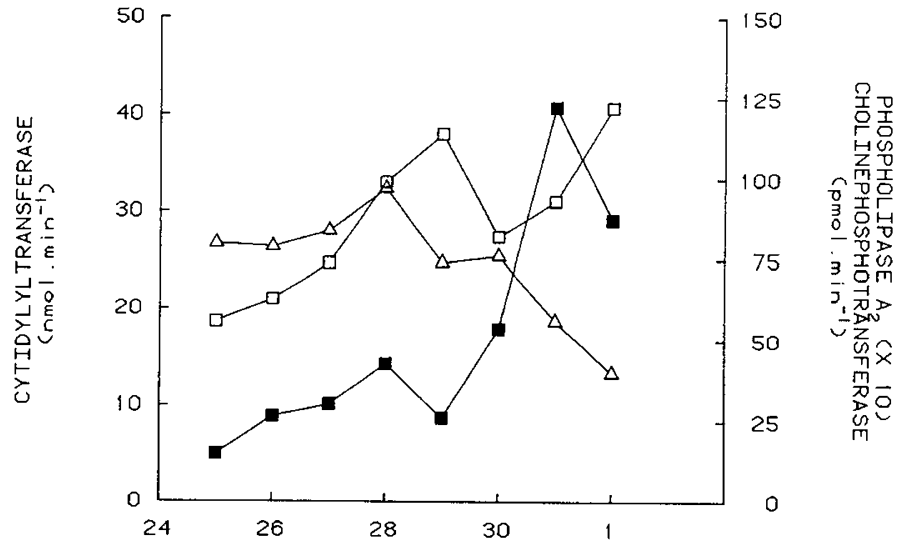

GESTATIONAL AGE (days)

Fig. 8. Developmental profiles of total enzyme activities in the fractions assayed, expressed on an activity per lung basis. Activities of

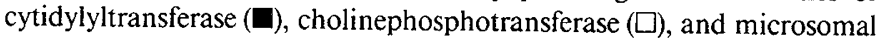
phospholipase $A_{2}(\Delta)$ were determined for each litter as described in "Materials and Methods," and are plotted as mean values for each time point.

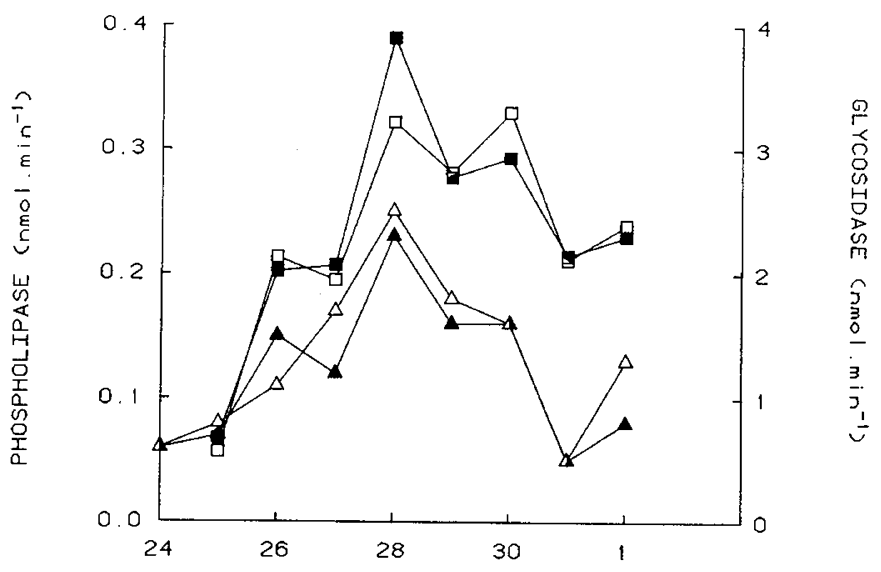

GESTATIONAL AGE (days)

Fig. 9. Developmental profiles of total enzyme activities in the lysosome soluble fraction, LS, expressed on an activity per lung basis. Activities of lysosomal phospholipase $A_{1}(\Delta)$ and $A_{2}(\boldsymbol{\Lambda}), \beta$-galactosidase $(\mathbb{\square})$, and $\beta$-glucuronidase ( $\square$ ) were determined for each litter as described in "Materials and Methods," and are plotted as mean values for each time point.

\section{DISCUSSION}

General patterns of enzyme activities and correlation with lung development. Most of the enzymes involved in the production of pulmonary surfactant have been studied in time course in the developing rabbit lung. The developmental profiles can be roughly classified as being of five general forms, as shown in Table 1 . There is a tendency for key enzymes catalysing reactions near the ends of metabolic pathways to show profiles of Forms 4 or 5 whereas enzymes involved in more fundamental processes are in the earlier groups.

The present study confirms the findings of Rooney et al. (45) that the activity of cytidylyltransferase rises just at birth in the rabbit (Fig. 1) whereas Tsao and Zachman (56) found a declining 
Table 1. Enzymes of surfactant production in developing rabbit lung, classified according to the form of the developmental time course

Enzyme References $\quad$ Suggested role

1) No significant change Acetyl-CoA carboxylase

Phosphatidate phosphatase (cytosol forms)

2) Declining from higher values in early gestation to lower values at and beyond term Glycogen synthase

Glycerol-3-phosphate phosphatidyltransferase (mitochondrial form) Choline kinase Phospholipase $\mathrm{A}_{2}$ (microsomal form)

3) Rising in late gestation to fall again at or before term Phosphorylase Fatty acid synthetase Phospholipase $\mathrm{A}_{2}$ (lysosomal form)

4) Rising in late gestation and retaining or resuming elevated values beyond term

Fatty acid elongation enzymes

Lysophosphatidate acyltransferase

Phosphatidate cytidylyltransferase

Glycerol-3-phosphate phosphatidyltransferase (microsomal form)

myo-inositol phosphatidyltransferase

Phosphatidate phosphatase (microsomal forms)

Lysophosphatidylcholine acyltransferase

Lysophosphatidylcholine:lysophosphatidylcholine acyltransferase

$11 \beta$-hydroxysteroid dehydrogenase

Adenylate cyclase (with activators)

5) Rising only at or just after birth

Phosphocholine cytidylyltransferase

Cholinephosphotransferase

* Data from this investigation.
19

2

20,45

45,56

2

13,19

*

19
45
20,32
20
6,20
$12,20,47$
45,56
56
37
$4,42,62$
$45, *$
$18,22,45$ *

Fatty acid synthesis

Phosphatidylcholine synthesis

Glycogen accumulation

Phosphatidylglycerol synthesis

Phosphatidylcholine synthesis

Phosphatidylcholine remodelling

Glycogen mobilisation

Fatty acid synthesis

Phosphatidylcholine remodelling

Fatty acid synthesis

Phospholipid synthesis

Acidic phospholipid synthesis

Phosphatidylglycerol synthesis

Phosphatidylinositol synthesis

Phosphatidylcholine synthesis

Phosphatidylcholine remodelling

Phosphatidylcholine remodelling

Control of surfactant secretion

Control of surfactant secretion

Phosphatidylcholine synthesis Phosphatidylcholine synthesis profile (Form 2). The profile determined here for cholinephosphotransferase (Fig. 2) has a significant rise after birth, as seen previously in some rabbit studies $(18,22,45)$, though not in others $(47,56)$. There is also an increase in late gestation (d 29), but this is limited to that single day (Fig. 2) so the variation of gestational stage for a given chronologic age will make it difficult to obtain a statistically significant result. This problem may explain the absence of a peak in the results of some rabbit investigations. In others, d 29 was not sampled $(47,56)$. These enzyme profiles can be set against other changes in developing rabbit lung. Kikkawa et al. (30) gave a detailed account of cytologic changes. Lamellar bodies first appear on d 25 and increased to fill all Type II cells by d 27 . On d 28, osmiophilic material appears in the alveolar lumina, and the amount rapidly increases until by d 31 all the alveolar spaces contain some. Also from $\mathrm{d} 28$, the fatty acid composition of lung phosphatidylcholine becomes mature $(17,38,49)$. The CDPcholine pool size reaches a peak on d 26 and 27 and falls thereafter $(43,54)$, an effect which could result from an increase in cholinephosphotransferase activity (Fig. 2).

Patterns of activity of phospholipases and other lysosomal enzymes. The present investigation is the first to examine phospholipase activities in developing rabbit lung. The declining profile of the alkaline-active phospholipase $A_{2}$ is shown in Figure 3. Melin et al. (34) studied a similar activity in the rat and found an increase through late gestation with elevated levels persisting in the neonate. The activity was measured on a postmitochondrial supernatant, with phosphatidylethanolamine as substrate. The enzyme activity was increased by the addition of lysed platelets (34). Rat platelets contain a phospholipase $A_{2}$ which is only active in the presence of an endogenous activating factor (16).

The acid-active phospholipase $\mathrm{A}_{2}$ from rabbit lung lysosomes shows an interesting profile (Fig. 4), with activity elevated from d 26-d 28. A rather similar pattern is seen for acid phospholipase $A_{1}$ (Fig. 5), an enzyme not obviously involved in remodelling processes. As two lysosomal enzymes showed profiles of this form, two further enzymes were examined: glycosidases with no known role in surfactant production. The profiles for $\beta$-galactosidase (Fig. 6) and $\beta$-glucuronidase (Fig. 7) were also of Form 3. The total activity patterns for these four enzymes can also be compared in Figure 9. One other possible lysosomal activity was investigated in developing rabbit lung. Bandstrup and Kretchmer (2) assayed a glucose-6-phosphatase at $\mathrm{pH} 6.6$, and reported that there was also activity against glycerol-3-phosphate. This acid phosphatase had a Form 3 profile with peak activity on d 26 and 27 . In human lung, $\beta$-galactosidase activity increased from wk 10 -wk 25 , as did acid phosphatase (48), but this period is rather early in gestation (equivalent to before $\mathrm{d} 19$ in the rabbit). There was no change in the activities of $\alpha$-galactosidase or $\alpha$-glucosidase (48). In the rat, $\alpha$-glucosidase and $\beta$ - $N$-acetylglucosaminidase showed little change in the lung during late gestation (8).

The general increase in lysosomal enzymes in developing rabbit lung would seem to indicate an increase in the number of lysosomes. One possibility is that this represents a change in the proportions of the cell types in the lung. The most effective change of this kind would be an increase in the number of macrophages; however, Zeligs et al. (64) found that the number of alveolar macrophages in fetal rabbit lung lavage was low until a few hours before birth, from which time there was a very marked and continued increase up to the 4th postnatal wk. Another possibility is that the increase in lysosomes is a consequence of their involvement in lamellar body formation and secretion. The idea of this involvement was first proposed by Sorokin (50) and by Kikkawa et al. (30) on the basis of cytologic studies. Cytochemical investigations and biochemical analyses have also shown the presence of lysosomal enzymes in lamellar bodies. The early work has been reviewed (23), and later studies 
have confirmed the findings for several species, and added more enzymes to the list $(24,26,27,51,52,63)$. It has also been demonstrated that the lysosomal enzyme activity in lamellar body preparations is not due to contamination with lysosomes $(28,39)$. The activity associated with lamellar bodies in immature human fetal lung explants increases as the tissue matures in culture (40). The possible roles of lysosomes in lamellar body development and surfactant secretion have been discussed (23, $24,25)$. The timing of increased lysosomal enzyme activity in the present study coincides with the commencement of surfactant secretion in the developing lung (30). An involvement of lysosomes in secretory processes has been suggested for several other tissues $(35,55)$.

The remodelling problem. This investigation of the development of phospholipase $A_{2}$ in the lung was undertaken in order to determine the importance of such enzymes in the remodelling of phosphatidylcholine. The first suggestions that remodelling processes might be involved in the synthesis of dipalmitoyl phosphatidylcholine in lung arose from observations of the incorporation of labeled precursors $(14,21,60)$. Incorporation studies have also shown that remodelling occurs in developing rabbit lung, particularly from d $28(1,22)$. Some studies of the substrate specificity of cholinephosphotransferase appeared to show that the enzyme was incapable of utilizing disaturated diacylglycerols, so that nearly all dipalmitoyl phosphatidylcholine would have to be produced by remodelling $(44,46)$. More recently, it has been found that cholinephosphotransferase can use dipalmitoylglycerol under appropriate conditions, and that the de novo formation of dipalmitoyl phosphatidylcholine is limited by the supply of dipalmitoylglycerol $(36,58)$. Remodelling is needed to increase the proportion of dipalmitoyl phosphatidylcholine to the level required for a functional surfactant.

Two routes of remodelling have been described. In the first, the unsaturated fatty acid at the 2-position of the phosphatidylcholine is removed by phospholipase $A_{2}$, and replaced with a palmitoyl residue transferred from palmitoyl-CoA by acylCoA:lysophosphatidylcholine acyltransferase (EC 2.3.1.23) (31). The second route again involves phospholipase $A_{2}$ action, but in this case the reacylation step is performed by lysophosphatidylcholine:lysophosphatidylcholine acyltransferase (15). This enzyme transfers a palmitoyl group from the 1-position of one lysophosphatidylcholine molecule to the vacant 2-position of another. Several studies have indicated that the first route is predominant in adult lung $(e . g ., 5,59)$. The transferase activity in the second route appears to be a side reaction of a lysophospholipase (EC 3.1.1.5) $(9,11)$.

Remodelling probably occurs at the level of the endoplasmic reticulum (61), but may occur later, perhaps even in the lamellar body (14). We have investigated both the mcirosomal phospholipase $\mathrm{A}_{2}$, presumably deriving from the endoplasmic reticulum, and also the lysosomal enzyme, part of the activity of which is located in the lamellar bodies $(24,28)$. As described above, the alkaline-active enzyme in the microsomes showed a steady decrease in activity from d 25 to newborn d 1, with no indication of a perinatal surge whereas the lysosomal hydrolase showed elevated activity from d 26-d 28, in parallel with the other lysosomal enzymes studied. It was suggested that this general rise in lysosomal enzyme activity indicates the presence of more lysosomes, coinciding with the beginning of surfactant secretion. The increased lysosomal involvement in lamellar body processing could cause an increased production of lysophosphatidylcholine from the action of phospholipase $\mathrm{A}_{2}$ on unsaturated phosphatidylcholine $(25,26)$. This would provide substrates for remodelling. Incorporation studies show remodelling to be an important process in developing rabbit lung from about d 28 (1, $22)$, and it is at this time that the specific activities of lysophosphatidylcholine:lysophosphatidylcholine acyltransferase (56) and acyl-CoA:lysophosphatidylcholine acyltransferase $(45,56)$ rise, reaching maximum values after birth.

\section{REFERENCES AND NOTES}

1. Abe, M., Akino, T., and Ohno, K.: On the metabolism of lecithin in lung and liver of fetal rabbits. Tohoku J. Exp. Med., 109: 163 (1973).

2. Bandstrup, N. and Kretchmer, N.: The metabolism of glycogen in the lungs of the fetal rabbit. Dev. Biol., 11: 202 (1965).

3. Barrett, A. J. and Heath, M. F.: Lysosomal enzymes. In: J. T. Dingle: Lysosomes. A Laboratory Handbook. 2nd ed., pp. 19-145 (North-Holland Publishing Co., Amsterdam, 1977).

4. Barrett, C. T., Sevanian, A., and Kaplan, S. A.: Adenylate cyclase activity in immature rabbit lung. Pediatr. Res., 8: 244 (1974).

5. Batenburg, J. J., Longmore, W. J., Klazinga, W., and van Golde, L. M. G.: Lysolecithin acyltransferase and lysolecithin: lysolecithin acyltransferase in adult rat lung alveolar type II epithelial cells. Biochim. Biophys. Acta, 573: 136 (1979).

6. Bleasdale, J. E., Wallis, P., Macdonald, P. C., and Johnston, J. M.: Changes in CDP-diglyceride:inositol transferase activity during rabbit lung development. Pediatr. Res., 13: 1182 (1979).

7. Bligh, E. G. and Dyer, W. J.: A rapid method of total lipid extraction and purification. Can. J. Biochem. Physiol., 37:911 (1959).

8. Bourbon, J. and Jost, A.: Control of glycogen metabolism in the developing fetal lung. Pediatr. Res., 16: 50 (1982).

9. Brumley, G. W. and van den Bosch, H.: Lysophospholipase-transacylase from rat lung: isolation and partial purification. J. Lipid Res., 18: 523 (1977).

10. Campbell, P. N. and Sargent, J. R.: Miscellaneous techniques. 1. Estimation of total protein by the method of Lowry et al. (1951). In: P. N. Campbell, J. R. Sargent: Techniques in Protein Biosynthesis. Vol. 1, pp. 299-300 (Academic Press, Inc., New York, 1967).

11. Casals, C., Acebal, C., Cruz-Alvarez, M., Estrada, P., and Arche, R.: Lysolecithin:lysolecithin acyltransferase from rabbit lung: enzymatic properties and kinetic study. Arch. Biochem. Biophys., 217: 422 (1982)

12. Casola, P. G. and Possmayer, F.: Pulmonary phosphatidic acid phosphohydrolase. Developmental patterns in rabbit lung. Biochim. Biophys. Acta, 655: 186 (1981).

13. Das, D. K.: Fatty acid synthesis in fetal lung. Biochem. Biophys. Res. Commun., 92: 867 (1980).

14. Engle, M. J., Sanders, R. L., and Longmore, W. J.: Evidence for the synthesis of lung surfactant dipalmitoyl phosphatidylcholine by a "remodelling" mechanism. Biochem. Biophys. Res. Commun., 94: 23-28 (1980).

15. Erbland, J. F. and Marinetti, G. V.: The enzymatic acylation and hydrolysis of lysolecithin. Biochim. Biophys. Acta, 106: 128 (1965).

16. Etienne, J., Grüber, A., and Polonovski, J.: Rat blood platelets activable phospholipases A2. Biochimie, 64: 377 (1982).

17. Gluck, L., Landowne, R. A., and Kulovich, M. V.: Biochemical development of surface activity in mammalian lung. III. Structural changes in lung lecithin during development of the rabbit fetus and newborn. Pediatr. Res., 4: 352 (1970).

18. Gluck, L., Sribney, M., and Kulovich, M. V.: The biochemical development of surface activity in mammalian lung. II. The biosynthesis of phospholipids in the lung of the developing rabbit fetus and newborn. Pediatr. Res., $1: 247$ (1967).

19. Gross, I. and Warshaw, J. B.: Enzyme activities related to fatty acid synthesis in developing mammalian lung. Pediatr. Res., 8: 193 (1974).

20. Hallman, M. and Gluck, L.: Formation of acidic phospholipids in rabbit lung during perinatal development. Pediatr. Res., 14: 1250 (1980).

21. Hallman, M. and Raivio, K.: Studies on the biosynthesis of disaturated lecithin of the lung: the importance of the lysolecithin pathway. Pediatr. Res., 8: 874 (1974).

22. Hallman, M. and Raivio, K. I.: Formation of disaturated lecithin through the lysolecithin pathway in the lung of the developing rabbit. Biol. Neonate, 27: 329 (1975).

23. Heath, M. F., Gandy, G., and Jacobson, W.: Lysosomes in the lung. In: J. T. Dingle and R. T. Dean: Lysosomes in Biology and Pathology. Vol. 5, pp. 33-58 (North-Holland Publishing Co., Amsterdam, 1976).

24. Heath, M. F. and Jacobson, W.: Phospholipases $A_{1}$ and $A_{2}$ in lamellar inclusion bodies of the alveolar epithelium of rabbit lung. Biochim. Biophys. Acta, 441: 443 (1976).

25. Heath, M. F. and Jacobson, W.: The action of lung lysosomal phospholipases on dipalmitoyl phosphatidylcholine and its significance for the synthesis of pulmonary surfactant. Pediatr. Res., 14: 254 (1980).

26. Heath, M. F. and Jacobson, W.: The nature of the phospholipases A of lung lamellar bodies. Pediatr. Res., 14: 846 (1980).

27. Hook, G. E. R.: Extracellular hydrolases of the lung. Biochemistry, 17: 520 (1978).

28. Hook, G. E. R. and Gilmore, L. B.: Hydrolases of pulmonary lysosomes and lamellar bodies. J. Biol. Chem., 257: 9211 (1982).

29. Kennedy, E. P. and Weiss, S. B.: The function of cytidine coenzymes in the biosynthesis of phospholipides. J. Biol. Chem., 222: 193 (1956)

30. Kikkawa, Y., Motoyama, E. K., and Gluck, L.: Study of the lungs of fetal and newborn rabbits. Am. J. Pathol., 52: 177 (1968).

31. Lands, W. E. M.: Metabolism of glycerolipids II. The enzymatic acylation of lysolecithin. J. Biol. Chem., 235: 2233 (1960).

32. Longmuir, K. J. and Johnston, J. M.: Changes in CTP: phosphatidate cytidylyltransferase activity during rabbit lung development. Biochim., Biophys. Acta, 620: 500 (1980).

33. Lowry, O. H., Rosebrough, N. J., Farr, A. L., and Randall, R. J.: Protein 
measurement with the Folin phenol reagent. J. Biol. Chem., 193: 265 (1951).

34. Melin, B., Maximilien, R., Friedlander, G., Etienne, J., and Alcindor, L. G.: Activités phospholipasiques pulmonaires du foetus de rat. Variations au cours du developpement. Biochim. Biophys. Acta, 486: 590 (1977).

35. Mellman, I.: Multiple pathways of membrane transport. Nature, 299: 301 (1982).

36. Miller, J. C. and Weinhold, P. A.: Cholinephosphotransferase in rat lung. The in vitro synthesis of dipalmitoylphosphatidylcholine from dipalmitoylglycerol. J. Biol. Chem., 256: 12662 (1981)

37. Nicholas, T. E., Johnson, R. G., Lugg, M. A., and Kim, P. A.: Pulmonary phospholipid biosynthesis and the ability of the fetal rabbit lung to reduce cortisone to cortisol during the final ten days of gestation. Life Sci., 22: 1517 (1978).

38. Ogino, H., Matsumara, T., Satouchi, K., and Saito, K.: Studies on molecular species of fetal lung lecithin by gas-liquid chromatography mass spectrometry. Biomed. Mass Spectrom., 4: 326 (1977)

39. Okazaki, T. and Johnston, J. M.: Distribution of the phosphatidate phosphohydrolase activity in the lamellar body and lysosomal fractions of lung tissue. Lipids, 15: 447 (1980).

40. Okazaki, T., Johnston, J. M., and Snyder, J. M.: Morphogenesis of the lamellar body in fetal lung tissue in vitro. Biochim. Biophys. Acta, 712: 283 (1982).

41. Oldenborg, V. and van Golde, L. M. G.: Activity of cholinephosphotransferase, lysolecithin:lysolecithin acyltransferase and lysolecithin acyltransferase in the developing mouse lung. Biochim. Biophys. Acta, 441: 433 (1976).

42. Powell, W. S. and Solomon, S.: Effect of prostaglandins on the adenylate cyclase activity of lungs from fetal rabbits. Endocrinology, 107: 1469 (1980)

43. Quirk, J. G., Bleasdale, J. E., Macdonald, P. C., and Johnston, J. M.: A role for cytidine monophosphate in the regulation of the glycerophospholipid composition of surfactant in developing lung. Biochem. Biophys. Res. Commun., 95: 985 (1980).

44. Rooney, S. A. and Wai-Lee, T. S.: Cholinephosphotransferase from rabbit lung microsomes. An improved assay and specificity towards exogenous diacylglycerols. Lung, 154: 201 (1977).

45. Rooney, S. A., Wai-Lee, T. S., Gobran, L., and Motoyama, E. K.: Phospholipid content, composition and biosynthesis during fetal lung development in the rabbit. Biochim. Biophys. Acta, $431: 447$ (1976).

46. Sarzala, M. G. and van Golde, L. M. G.: Selective utilization of endogenous unsaturated phosphatidylcholines and diacylglycerols by cholinephosphotransferase of mouse lung microsomes. Biochim. Biophys. Acta, 441: 423 (1976).

47. Schultz, F. M., Jimenez, J. M., Macdonald, P. C., and Johnston, J. M.: Fetal lung maturation. I. Phosphatidic acid phosphohydrolase in rabbit lung. Gynecol. Invest. 5: 222 (1974).

48. Shin-Buering, Y. S., Dallinger, M., Osang, M., Rahm, P., and Schaub, J.: Lysosomal enzyme activities of human fetal organs during development. Biol. Neonate, 38: 300 (1980).

49. Soodsma, J. F., Mims, L. C., and Harlow, R. D.: The analysis of the molecular species of fetal rabbit lung phosphatidylcholine by consecutive chromatographic techniques. Biochim. Biophys. Acta, 424: 159 (1976).

50. Sorokin, S. P.: A morphologic and cytochemical study on the great alveolar cell. J. Histochem. Cytochem., 14:884 (1967).

51. Spicer, S. S., Frayser, R., Virella, G., and Hall, B. J.: Immunocytochemical localization of lysozymes in respiratory and other tissues. Lab. Invest., 36:
282 (1977)

52. Spitzer, H. L., and Johnston, J. M.: Characterization of phosphatidate phosphohydrolase activity associated with isolated lamellar bodies. Biochim. Biophys. Acta, 531: 275 (1978).

53. Sundler, R.: Ethanolaminephosphate cytidylyltransferase. Purification and characterization of the enzyme from rat liver. J. Biol. Chem., 250: 8585 (1975).

54. Tokmakjian, S., Haines, D. S. M., and Possmayer, F.: Pulmonary phosphatidylcholine biosynthesis. Alterations in the pool sizes of choline and choline derivatives in rabbit fetal lung during development. Biochim. Biophys. Acta, 663: 557 (1981).

55. Trifaro, J. M. and Poisner, A. M.: Common properties in the mechanisms of synthesis, processing and storage of secretory products. In: A. M. Poisner and J. M. Trifaro: The Secretory Granule. pp. 387-407 (Elsevier Biomedical Press, Amsterdam, 1982).

56. Tsao, F. H. C. and Zachman, R. D.: Phosphatidylcholine-lysophosphatidylcholine cycle pathway enzymes in rabbit lung. II. Marked differences in the effect of gestational age on activity compared to the CDP-choline pathway. Pediatr. Res., 11: 858 (1977).

57. van Golde, L. M. G.: Metabolism of phospholipids in the lung. Am. Rev. Respir. Dis., 114: 977 (1976).

58. van Heusden, G. P. H. and van den Bosch, H.: Utilization of disaturated and unsaturated phosphatidylcholines and diacylglycerols by cholinephosphotransferase in rat lung microsomes. Biochim. Biophys. Acta, 711:361 (1982).

59. van Heusden, G. P. H., Vianen, G. M., and van den Bosch, H.: Differentiation between acyl coenzyme A: lysophosphatidylcholine acyltransferase and lysophosphatidylcholine:lysophosphatidylcholine transacylase in the synthesis of dipalmitoyl phosphatidylcholine in rat lung. J. Biol. Chem., 255: 9312 (1980).

60. Vereyken, J. M., Montfoort, A., and van Golde, L. M. G.: Some studies on the biosynthesis of the molecular species of phosphatidylcholine from rat lung and phosphatidylcholine and phosphatidylethanolamine from rat liver. Biochim. Biophys. Acta, 260: 70 (1972).

61. Voelker, D. R. and Snyder, F.: Subcellular site and mechanism of synthesis of disaturated phosphatidylcholine in alveolar type II cell adenomas. J. Biol. Chem., 254: 8628 (1979)

62. Whitsett, J. A., Manton, M. A., Darovec-Beckerman, C., Adams, K. G., and Moore, J. J.: $\beta$-Adrenergic receptors in the developing rabbit lung. Am. J. Physiol., 240: E351 (1981).

63. Williams, C. H.: The isolation of lung lamellar bodies. Methods Enzymol., 31: 419 (1974).

64. Zeligs, B. J., Zeligs, J. D., Nerurkar, L. S., and Bellanti, J. A.: Maturation of the rabbit alveolar macrophage during animal development. 1. Perinatal influx into alveoli and ultrastructural differentiation. Pediatr. Res., 11: 197 (1977).

65. Requests for reprints should be addressed to: Dr. M. F. Heath: Dept. of Paediatrics, Level 8, Addenbrooke's Hospital, Hills Road, Cambridge, CB2 2QQ, United Kingdom.

66. This research was supported by Medical Research Council and the Children's Research Fund, who are gratefully acknowledged. W.J. is a Sir Halley Stewart Professor of Medical Research.

67. Received for publication January 24, 1983.

68. Accepted for publication July 14, 1983 